\title{
SELF-REGENERATING HYBRID ANION EXCHANGE PROCESS FOR REMOVING RADIUM, BARIUM and STRONTIUM FROM THE MARCELLUS PRODUCED WASTEWATER USING ONLY ACID MINE DRAINAGE (AMD)
}

\author{
SUPPLEMENTARY INFORMATION
}

Jinze Li (iilb12@lehigh.edu) and Arup K. SenGupta*(arup.sengupta@lehigh.edu)

Department of Civil and Environmental Engineering

Lehigh University, Bethlehem PA 18015

Phone: (610)758-3534

Research article for ES\&T Water

August 25, 2020 
Availability of AMD Streams. The Geographical advantage for Marcellus shale flowback treatment using AMD streams will greatly mitigate the costs and environmental risks (Figure SI1). Copious amount of AMD surrounded by shale gas wells make it possible for onsite flowback treatment and reuse.

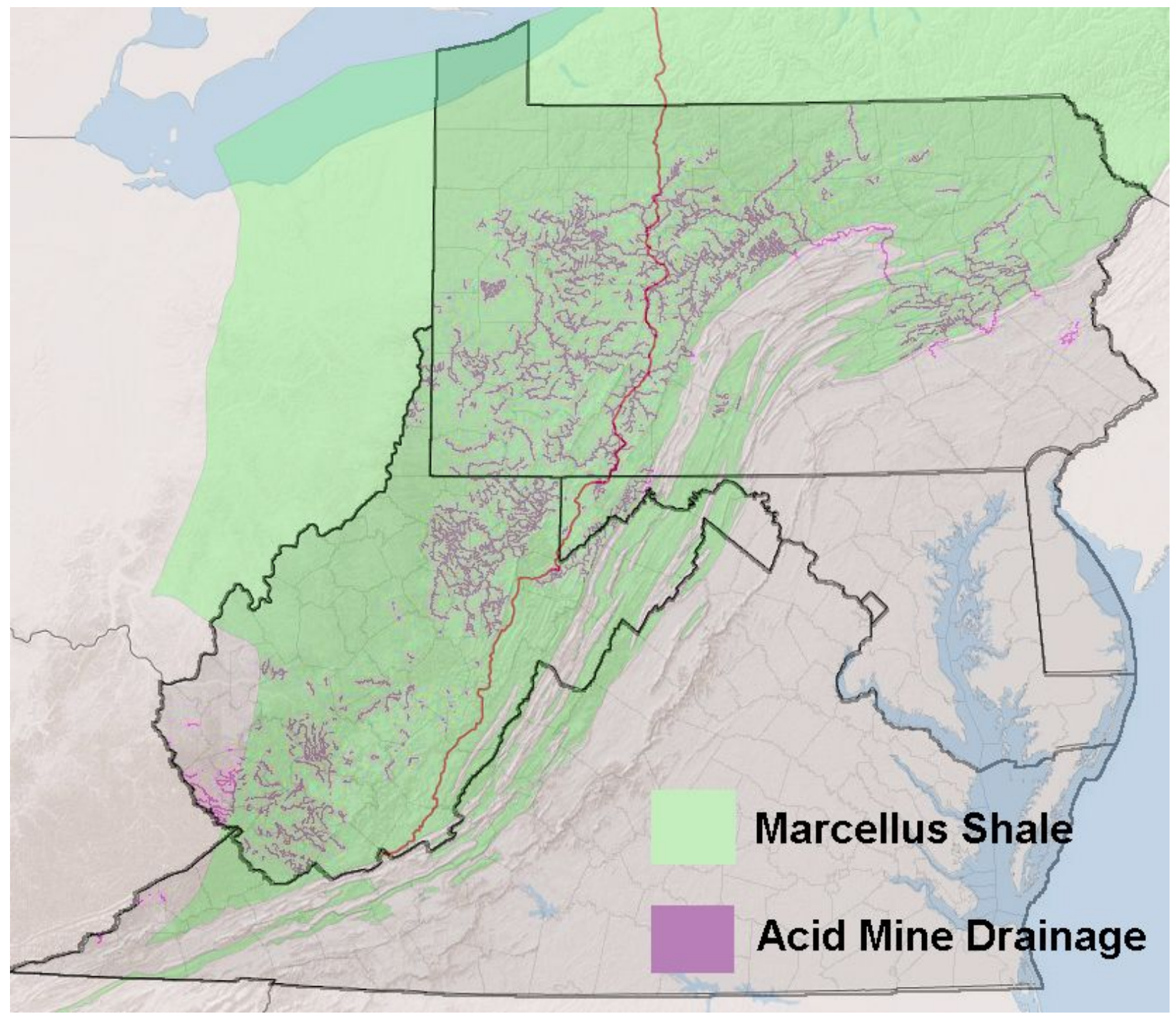

Figure SI-1. The location of Marcellus shale region and acid mine drainage (AMD) streams.

\section{GPS Coordinates of AMD and Marcellus Produced Water sampling Locations of the}

Study. The sulfate concentration of each AMD sample was analyzed and marked with red circles in Figure SI-2. Bigger radius represents higher sulfate concentration. The water sample from AMD site 3 (sulfate concentration = $195 \mathrm{mg} / \mathrm{L}$ ) was used in the study to emphasize the 
advantage of dilution less co-precipitation of radium, barium, and strontium using selfregenerating ion exchange technique.

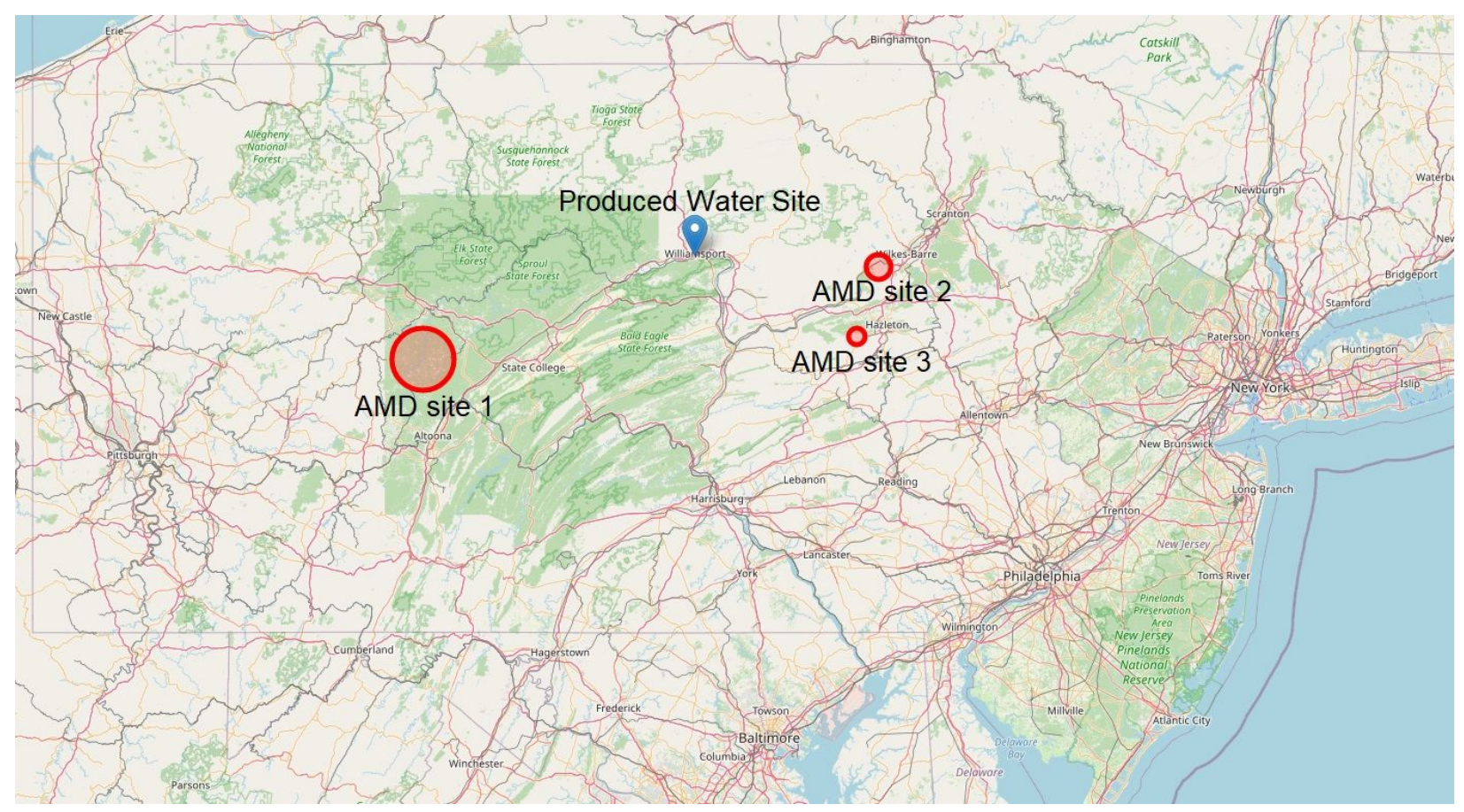

Figure SI-2. The sampling locations of Marcellus produced water and acid mine drainage (AMD) streams. The radius of red circle marker denotes the AMD sample's sulfate concentration.

$\mathrm{ZrO}_{2}$ assisted high specific gravity. Parent anion exchanger cannot be used in Marcellus shale produced water treatment process because of the high specific gravity of produced water (1.16). However, by doping $\mathrm{ZrO}_{2}$ into the anion exchanger can significantly increase the resin density from 1.08 to 1.35 thus becoming heavier than produced water (Figure SI-3). 


\section{Parent lon Exchange Resin Floating on Flowback Water}

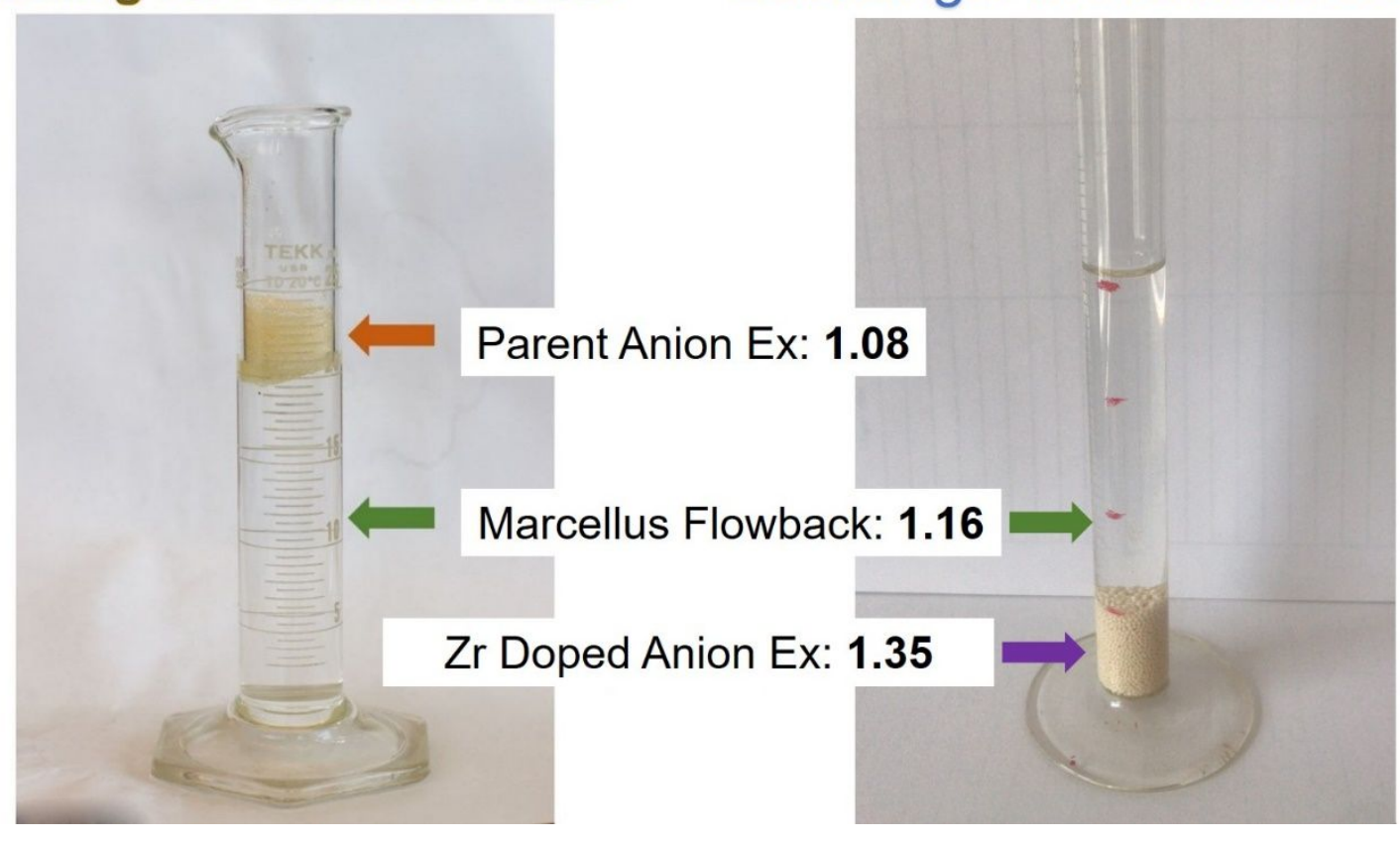

\section{Zirconium Doped Ion Exchanger in Flowback Water}

Figure SI-3. Specific gravity of $\mathrm{ZrO}_{2}$ nanoparticles increased to 1.35 , while the parent anion exchanger has a specific gravity of 1.08 .

Dilution Effect with Regular AMD. The $\mathrm{SO}_{4}{ }^{2-}$ could be either added with sulfate salt, such as $\mathrm{Na}_{2} \mathrm{SO}_{4}$, or blended with water which already contains sulfate ions. However, there are shortages for both methods. When adding salt, people also add sodium to the water, which will increase the TDS further. For directly blending with another water body that is rich in sulfate, such as acid mine drainage (AMD), it cannot be controlled as the removal efficiency is depend on the solubility product for all the sulfate precipitations. To get stoichiometric sulfate ions on a charge basis, the process could produce a large volume of treated water. Figure SI-4 shows the finished flowback water volume after removing all barium, strontium, and radium using an AMD resource with different sulfate concentrations. In our case, the sulfate concentration in the AMD is $195 \mathrm{mg} / \mathrm{L}$. The treated flowback volume is over 90 -fold, which exceeded the demand for 
hydrofracking makeup. It is impossible to send it back to AMD sites due to the increased residual TDS.

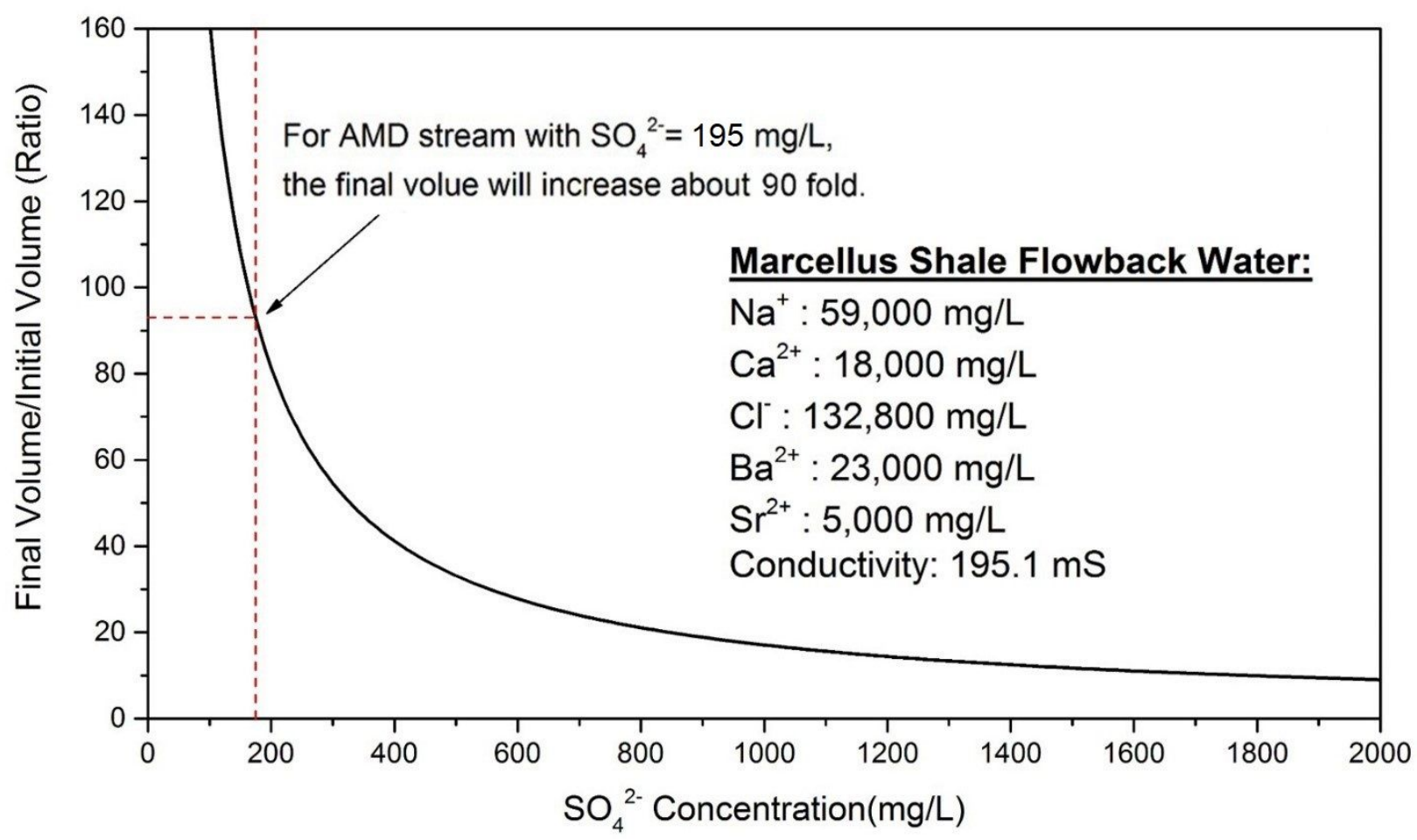

Figure SI-4. A model illustrating the final volume of treated flowback if radium, barium, and strontium are mostly removed by directly mixing with AMD water regarding its sulfate concentration. The water analysis of flowback sample is showed in the figure.

PHREEQC Assisted High Purity Solid Separation. Radium sulfate has much lower solubility product than barium and strontium sulfate. However, barium and strontium concentrations are much greater than radium in the produced water. As a result, barium and strontium precipitations are initiated earlier than radium. PHREEQC model (Halim et al., 2005) was used to model the precipitation sequence of divalent cations. Figure SI-5 shows the summary of results from PHREEQC; note that the precipitation sequence follows $\mathrm{BaSO}_{4}>\mathrm{SrSO}_{4}>\mathrm{RaSO}_{4}$. 
The proposed self-regenerating system should preferably be located near the gas well mouth and the treated AMD is suitable for hydraulic fracturing.

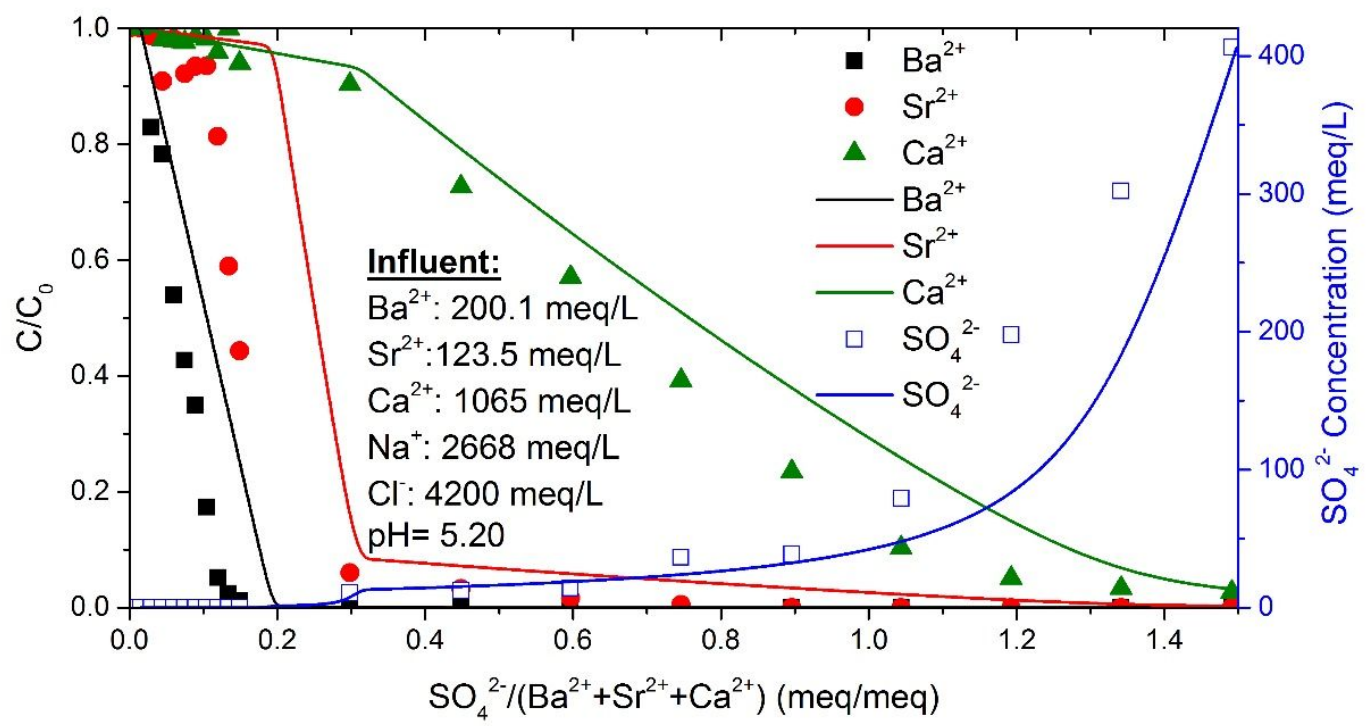

Figure SI-5. Experimental data versus PHREEQC modeling for precipitation orders regarding sulfate ion concentration.

Laboratory Experimental Setup. The experimental setup in the laboratory is showed in Figure SI-6, where AMD water is contained in a plastic bucket at room temperature. Flowback water is contained in a plastic container after aeration and filtration to remove the total suspended solids (TSS). 


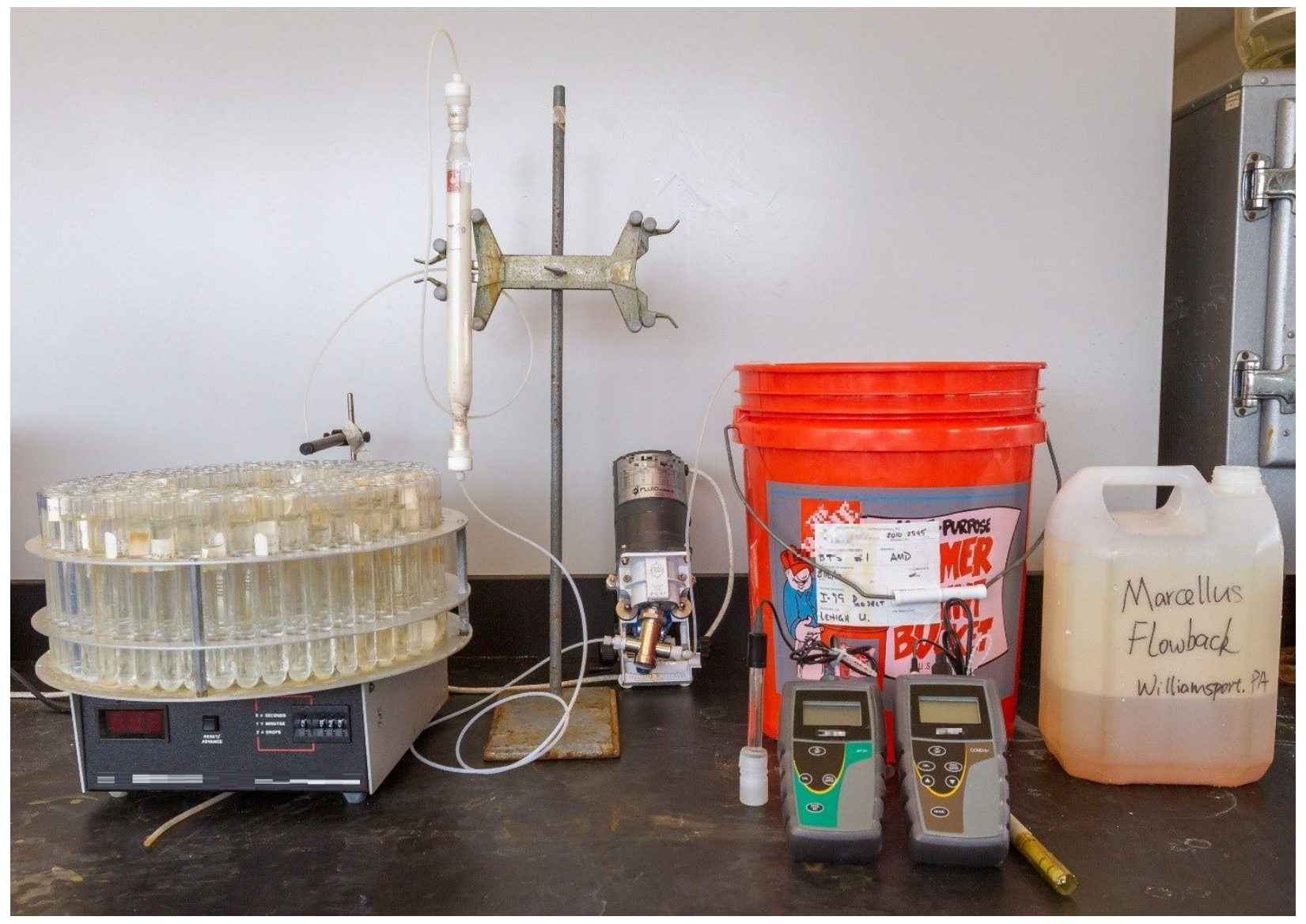

Figure SI-6. Experimental setup in the laborotary to treat shale gas flowback water using AMD.

AMD is at times contaminated with trace amounts of toxic metals and metalloids and of them, arsenate or $\mathrm{As}(\mathrm{V})$ poses some unusual problems because it exists primarily as an anion and quite soluble at neutral to alkaline $\mathrm{pH}$. If arsenic is not removed and the treated AMD is used for hydrofracturing, the gas wells are likely to be contaminated on a long-term basis. Figure SI-7 shows column run data where AMD was spiked with $200 \mu \mathrm{g} / \mathrm{L}$ of $\mathrm{As}(\mathrm{V})$ and run through HIXNanoZr for two consecutive cycles of operation. No arsenic leakage is observed after 400 bed volumes whereas the parent Purolite A850 (without Zr loading) was unable to remove arsenic selectively. The underlying science of selective removal of arsenic by HIX-NanoZr has earlier been discussed and it was demonstrated that zirconium oxide nanoparticles in HIX-NanoZr are 
the primary sorption sites where arsenate and/or arsenite remains selectively bound(Padungthon et al., 2014; Smith et al., 2015).

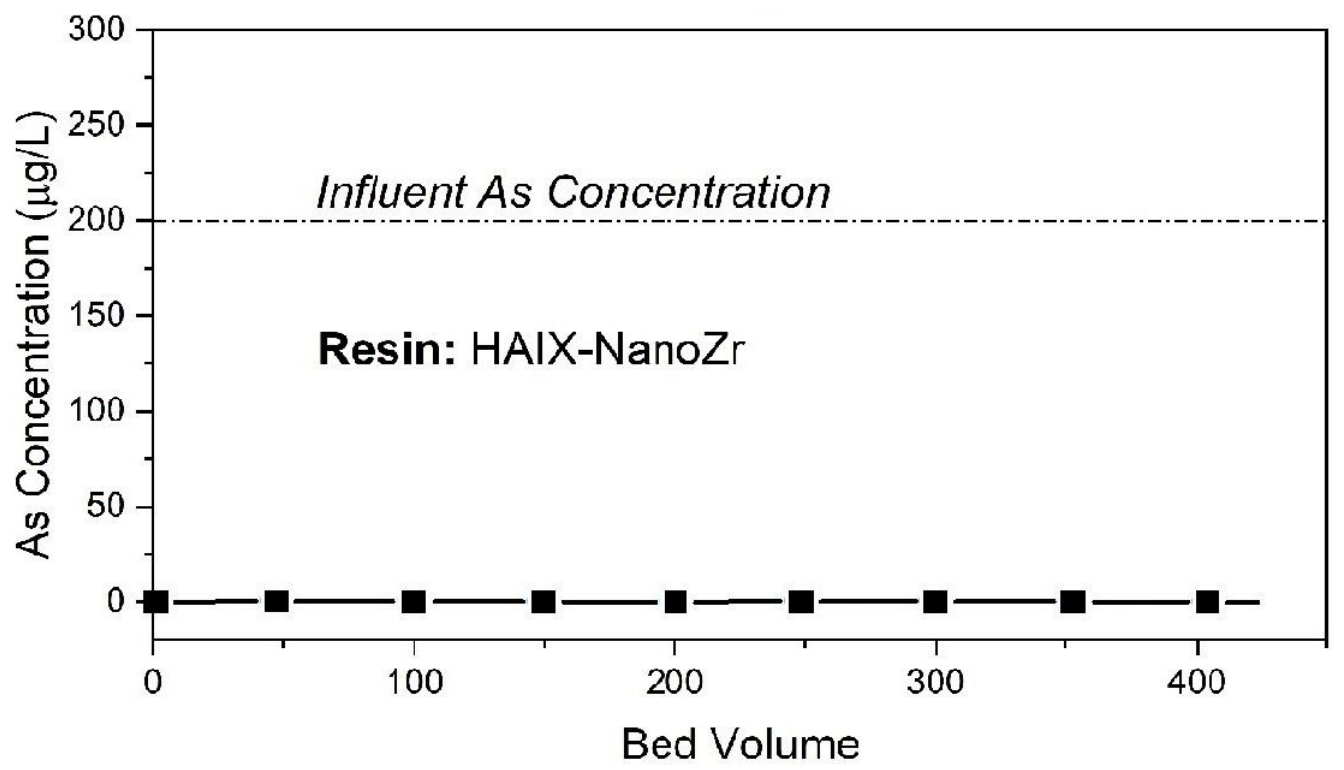

Figure SI-7. Arsenic removal test of HIX-NanoZr during AMD cycle with spiked $200 \mu \mathrm{g} / \mathrm{L}$ As in AMD stream.

Quantitative Effect of The Donnan Exclusion Effect. Let us consider the HAIX resin with a capacity (fixed positive charges of quaternary ammonium functional group or $\mathrm{R}_{4} \mathrm{~N}^{+}$) of $1.0 \mathrm{M}$ in sulfate form. lonic strength or molar concentration of the AMD is appromately $4.0 \mathrm{mM}$.

The concept of Donnan potential can be applied to estimate the exchanger-phase concentration of $\mathrm{Ba}^{2+}$ (Cumbal and SenGupta, 2005).

Derivation of the Interfacial $\mathrm{pH}$ Relationship.

The PLE is an anion exchanger with fixed positive charges contributed by immobilized copper(II) in the polymer phase. The concept of Donnan potential can be applied to estimate the 
polymer-phase $\mathrm{pH}$. At equilibrium, the electrochemical potential $\left(\eta_{i}\right)$ for an ion "i" in the aqueous phase is equal to that in the polymer phase, i.e.,

$$
\eta_{i}=\overline{\eta_{i}}
$$

Where the overbar denotes the resin phase.

Again, electrochemical potential of "i" is equal to the sum of its chemical potential $\left(\mu_{i}\right)$ and electric potential $(\phi)$ in individual phases, thus,

$\mu_{i}^{0}+R T \ln a_{i}+z_{i} F \phi=\mu_{i}^{0}+R T \ln \overline{a_{i}}+z_{i} F \bar{\phi}$

Where $\mu_{i}^{0}$ is the chemical potential of "i" in the standard states, $\mathrm{R}$ is the universal gas constant, $T$ is the absolute temperature, $a_{i}$ is the activity of " $i$ ", $z_{i}$ is the electric charge of "i", $F$ is the Faraday constant, $\phi$ is the electric potential, and overbars denote the resin phase.

The Donnan potential results from the difference in the activity of the ionic species between the two phases and is equal to

$$
E_{\text {Don }} \equiv \bar{\phi}-\phi=\frac{R T}{z_{i} F} \stackrel{\substack{a_{i} \\ a_{i}}}{=}
$$

Applying eq SI-3 for divalent sulfate (i.e., $z_{i}=-2$ ), we have

$$
E_{\text {Don }}=-\frac{R T}{2 F} \ln \frac{a_{S}}{a_{S}}
$$

Where subscript "S" represents sulfate.

Applying similar treatment for $\mathrm{Ba}^{2+}\left(\right.$ i.e., $\mathrm{z}_{\mathrm{i}}=+2$ )

$E_{\text {Don }}=\frac{R T}{2 F} \ln \frac{a_{B a}}{\overline{a_{B a}}}$

In the absence of any externally applied electric potential gradient at equilibrium, the equality of (SI-4) and (SI-5) leads to the following: 


$$
\overline{a_{B a}}=\frac{a_{S}}{\overline{a_{S}}} \cdot a_{B a}
$$

Considering ideality, activities are replaced by molar concentration i.e., $C_{i}$ and $\overline{C_{i}}$,

$\overline{C_{B a}}=\frac{C_{S}}{\overline{C_{S}}} \cdot C_{B a}$

$\overline{C_{S}} \simeq 1.0 M$ while in AMD, $C_{i}=4 \times 10^{-3} M$ considering a very conservative case where $\mathrm{CBa}$ is equal to $\mathrm{C}_{\mathrm{S}}$,

$$
\overline{C_{B a}}=\frac{C_{S}}{\overline{C_{S}}} \cdot C_{B a}=\frac{\left(4 \times 10^{-3}\right)\left(4 \times 10^{-3}\right)}{1.0}=1.6 \times 10^{-5} \mathrm{M}=2.2 \frac{\mathrm{mg}}{\mathrm{L}} \text { as } \mathrm{Ba}
$$

HAIX-NanoZr Capacity Change. The zirconium nanoparticles are brighter in the SEM (Figure SI-8A) due to its higher atomic number. The size is estimated to be $50-200 \mathrm{~nm}$. The particles reside in the ion exchanger phase rather than the pore structures, which produce less impact to the fixed functional groups. The zirconium oxide nanoparticles doped inside the resin did not change the pore structure, thus not influencing the ion exchange capacity (Figure SI-8B). 


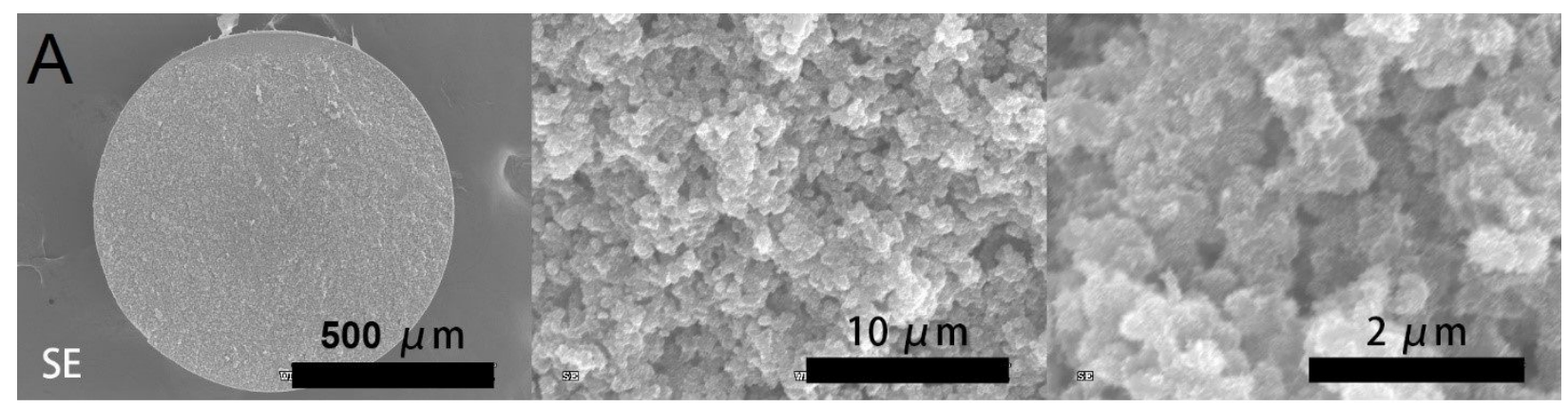

B

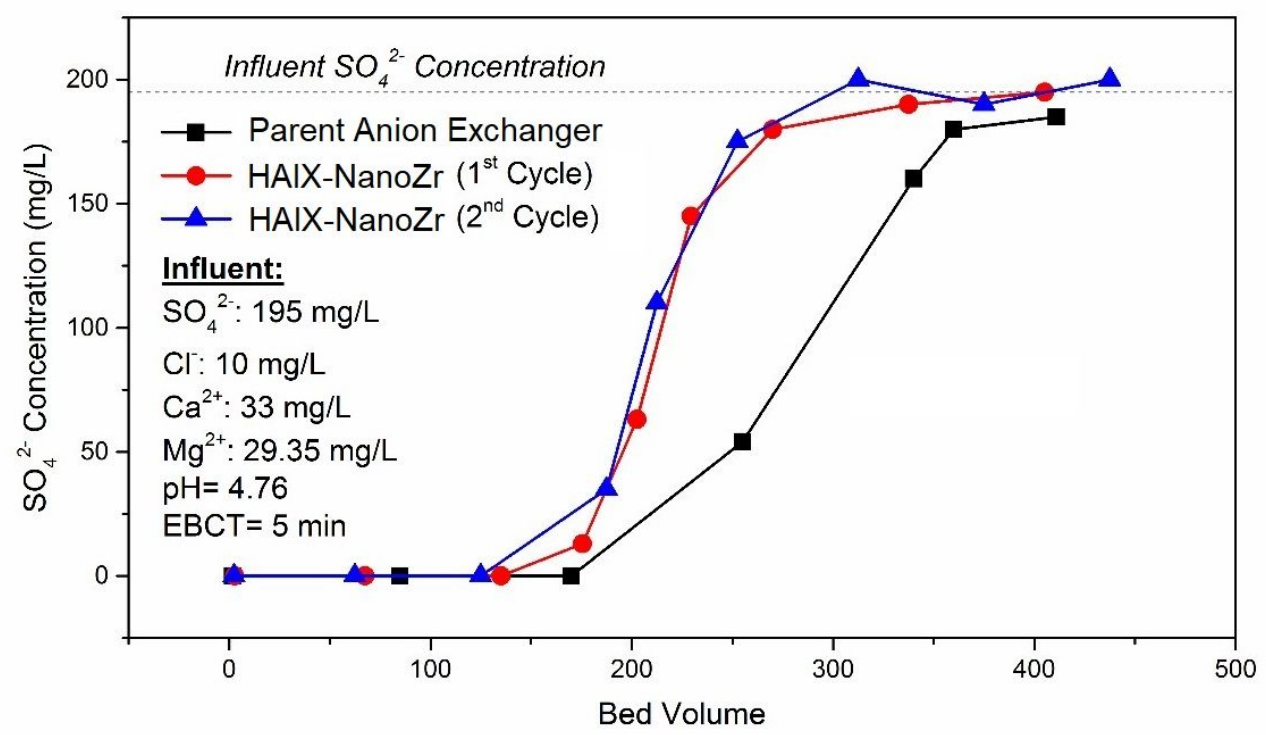

Figure SI-8. (A) SEM photos of zirconium doped hybrid anion exchanger. The scale bars are showed in each picture; (B) Comparison of ion exchange capacity of HAIX-NanoZr and parent anion exchanger in column cycles.

Ion Exchange Induced Supersaturation (IXISS) Effects. The prolonged precipitation of barite and celestite is possibly due to the explanations listed as follows:

i) The fixed functional groups with positive charges react as compete ions to combine with sulfate in place of barium and strontium. It is difficult for barium and strontium ions with positive charges to approach the ion exchange site with quaternary ammonium functional groups;

ii) Lack of crystallization seeds within the resin matrix will prevent the precipitation; 
iii) The resin matrix consists of organic matter will increase the interfacial tension between the crystal and aqueous solution thus prolonging the induction time;

iv) The crystal growth rate will be inhibited by bonded resin matrix thus cannot grow to a visible size.

\section{References}

Cumbal, L., SenGupta, A.K., 2005. Arsenic Removal Using Polymer-Supported Hydrated Iron(III) Oxide Nanoparticles: Role of Donnan Membrane Effect †. Environ. Sci. Technol. 39, 6508-6515. https://doi.org/10.1021/es050175e

Halim, C.E., Short, S.A., Scott, J.A., Amal, R., Low, G., 2005. Modelling the leaching of Pb, Cd, As, and Cr from cementitious waste using PHREEQC. J. Hazard. Mater. 125, 45-61. https://doi.org/10.1016/j.jhazmat.2005.05.046

Padungthon, S., Li, J., German, M., SenGupta, A.K., 2014. Hybrid Anion Exchanger with Dispersed Zirconium Oxide Nanoparticles: A Durable and Reusable Fluoride-Selective Sorbent. Environ. Eng. Sci. 31, 360-372. https://doi.org/10.1089/ees.2013.0412

Smith, R.C., Li, J., Padungthon, S., Sengupta, A.K., 2015. Nexus between polymer support and metal oxide nanoparticles in hybrid nanosorbent materials (HNMs) for sorption/desorption of target ligands. Front. Environ. Sci. Eng. 9, 929-938. https://doi.org/10.1007/s11783-0150795-9 